\title{
Supervisão pedagógica na formação académica: conceções dos estudantes de Serviço Social
}

Hélia Bracons'

\author{
Submetido em \\ $30 / 1 / 2016$ \\ Aceite em \\ $18 / 1 / 2017$
}

Resumo: O principal objetivo deste trabalho pretende percecionar o papel e o trabalho do supervisor pedagógico, bem como do supervisor institucional no processo de formação dos estudantes de Serviço Social. Procurámos conhecer as conceções dos estudantes finalistas da licenciatura em Serviço Social. Os estudantes foram sujeitos a um guião de entrevista sobre supervisão pedagógica, importância do estágio no processo de formação, principais competências do supervisor pedagógico e supervisor institucional e o papel do supervisor pedagógico numa pedagogia para a autonomia. As conclusões permitem verificar que a supervisão tutorial adquire um papel ativo de interação, partilha e mediação entre o professor e o aluno e a relação e interação partilhada com o supervisor institucional, é a via privilegiada de conhecimento e de aperfeiçoamento na formação em Serviço Social.

Palavras-chave: supervisão pedagógica, relação pedagógica, estágio académico, serviço social.

Abstract: The main goal of this presentation intends to perceive the role and the work of the educational supervisor and institutional advisor, in the process of training the students of Social Service. We sought to investigate the conceptions of the undergraduates of the degree course in Social work. These students were subjected to a pedagogic supervision interview guide, trying to sense the importance of the training course in the training process, the core competences of the tutorial and institutional advisor and the role of the supervisor in teaching pedagogy for autonomy. The conclusions show that orientation tutorial acquires an active role of interaction, sharing and mediation between the teacher and the student, and the relationship and shared interaction with institutional Advisor is a privileged medium of gaining knowledge and improvement in training in social work.

Keywords: pedagogic supervision, pedagogic relationship, internship, social work.

1 Doutora em Serviço Social. Professora Auxiliar no Instituto de Serviço Social da ULHT. Coordenadora conjunta dos Estágios da Licenciatura em Serviço Social. Investiga sobre competências culturais, interculturalidade, metodologia de investigação e supervisão pedagógica. 


\section{Introdução}

A supervisão pedagógica é um processo de construção, reflexão e de aplicação prática das capacidades de observação, de análise e de criatividade dos estudantes em contexto de formação académica. Procurámos conhecer as conceções dos estudantes finalistas da licenciatura em Serviço Social através de uma metodologia de análise de conteúdo, e interpretar a sua visão perante a problemática estabelecida. Estes estudantes foram sujeitos a um guião de entrevista sobre supervisão pedagógica, importância do estágio no processo de formação, principais competências do supervisor tutorial e institucional e o papel do supervisor pedagógico numa pedagogia para a autonomia.

\section{Breve reflexão sobre supervisão pedagógica na formação académica}

\subsection{Conceito de supervisão pedagógica}

Segundo Moreira (2004), a supervisão pedagógica institui-se como instrumento de transformação dos sujeitos e das suas práticas, com implicações nos contextos (i)mediatos da ação pedagógica. 0 exercício da supervisão, numa orientação educativa privilegia a promoção da autonomia do aluno e um desenvolvimento profissional de natureza reflexiva. Isto implica uma redefinição do papel do supervisor. O supervisor deve ser um profissional com competências não apenas na sua área disciplinar, mas também em didática e em supervisão (Moreira, 2004, p. 141). Conforme Vieira (2009), na expressão "supervisão pedagógica”, o adjetivo reporta-se não apenas ao objeto da supervisão - a pedagogia -, mas também à sua função potencialmente educativa.

Entende-se que a supervisão, quando orientada por uma visão crítica de pedagogia, torna a ação pedagógica mais consciente, deliberada e suscetível à mudança, permitindo o reconhecimento da sua complexidade e incerteza e impedindo a formulação de soluções técnicas e universais para os problemas "pantanosos" que nela se colocam (Schön, 1987, apud Vieira, 2009).

Na perspetiva de Alarcão \& Tavares (2003, apud Soares (s/d, p. 6) "O objetivo da supervisão não é apenas o desenvolvimento do conhecimento, visa também o desabrochar de capacidades reflexivas e o repensar de atitudes, contribuindo para uma prática de ensino mais eficaz, mais comprometida, mais pessoal e mais autêntica". 
Refletir sobre as práticas é ter como objeto de reflexão: contextos, conteúdos, finalidades de ensino, conhecimentos, capacidades, fatores inibidores da aprendizagem nos alunos, envolvimento no processo de avaliação, razão de ser do professor e dos papéis que assume (Moreira e al., 2001 apud Soares (s/d).

Alarcão \& Tavares (2007 apud Prates et al, 2010, p. 23) defendem que "o supervisor tem de desenvolver nos supervisionados capacidades e atitudes, tendo em conta a qualidade e a excelência, reforçando a ideia de que a supervisão é uma ação multifacetada, faseada, continuada e cíclica”.

\subsection{O papel do estágio no processo de formação em Serviço Social}

Não podemos esquecer que colocar o aluno em contexto prático implica o exercício e aquisição de competências teóricas, cognitivas, analíticas, de comunicação e interação, assim como uma atitude de responsabilidade individual, social e coletiva. O estágio é o espaço privilegiado de aprendizagem que possibilita ao estudante vivenciar experiências que contribuem não só para a sua formação, mas para a construção da sua identidade pessoal e profissional.

Como espaço de aprendizagem e de partilha de conhecimentos, o estágio constitui-se como campo de partilha, análise das práticas e de reflexão crítica e constante. Permite o confronto com o real através de uma vivência pessoal. 0 estágio é um período de formação prática realizada em serviços e instituições, com vista a uma aprendizagem no "terreno" e efetuado sob orientação.

Conforme Granja, (2005 apud Freitas, 2013) “O estágio torna-se uma instância de reconstrução de saber/conhecimento. A partir do saber processual e procedimental, o saber da ação produz um saber legitimado. Como instância de articulação fecunda entre a teoria e a prática, o estágio exige do estudante exercício teórico multi-, inter- e transdisciplinar em resposta à diversidade complexa da realidade social que não é compreendida por uma única ciência".

O estágio define-se como o processo de aprendizagem do saber agir e constitui-se como um dispositivo pedagógico fundamental para as aprendizagens das práticas profissionais (Granja, 2005 apud Freitas, 2013). Segundo Granja (2005), o estágio (...) requer constante reflexão e capacidade crítica, a partir da complexidade da vida social e do contacto do estudante com a realidade. Favorece a transferência de saberes. É através dele que o conhecimento se concretiza na conjugação dos saberes dos sujeitos com a reflexão pela síntese do conhecimento adquirido (Freitas, 2013, p. 75). 
Buriolla (2001) refere que a importância do professor supervisor de campo e supervisor académico é ímpar, pois a figura deles contribuirá para "direcionar" um novo profissional que, na maioria das vezes, será influenciado pelos mesmos. Devido a isto, espera-se que estes profissionais tenham uma postura ética e comprometida com o desenvolvimento e cidadania dos usuários, buscando a emancipação dos mesmos e o resgate de sua cidadania enquanto sujeitos, rompendo com aquela visão do assistente social burocrático e assistencialista (apud Almeida, s/d, p. 4). "O estágio é o locus onde a identidade profissional do aluno é gerada, construída e referida; volta-se para o desenvolvimento de uma ação vivenciada, reflexiva e crítica e, por isso, deve ser planejado gradativamente e sistematicamente" (Buriolla, 2001, p.13, apud Almeida, s/d, p. 5).

Buriolla (2001 apud Almeida, s/d. p. 5) afirma ainda que o estágio é essencial à formação do académico, pois lhe proporciona momentos específicos de aprendizagem, reflexão sobre a ação profissional, uma visão crítica da dinâmica das relações existentes na instituição (...), possibilitando ao estudante a elaboração de novos conhecimentos.

Na perspetiva de Freitas (2013) o estágio também permite ao estudante proporcionar o estabelecimento e o contato de relações com outros profissionais, possibilita resolver problemas, tomar decisões e desenvolver perspetivas críticas relativamente à sua profissão.

O estágio em Serviço Social ocupa um lugar importante na formação e faz parte integrante dela. Os estágios da licenciatura em Serviço Social constituem atividade pedagógica de caracter obrigatório e desenvolvem-se no $2^{\circ}$ e $3^{\circ}$ anos com duração e ECTS de acordo com o programa curricular em vigor.

De acordo com o Regulamento de Estágio da licenciatura em Serviço Social da Universidade onde foi efectuado o presente estudo, os estágios são concebidos como instância de formação experiencial, como espaços de aprendizagem do processo de intervenção, através da relação teoria/prática. Neles, os alunos são confrontados com as condições concretas do real e com a necessidade de as interpretar para poder agir.

\subsection{A importância da relação pedagógica no percurso e no processo de aprendizagem}

Como já referido, o estágio desenrola-se sob orientação de um profissional da área, designado como supervisor tutorial, que tem uma função científico-peda- 
gógica: é um docente com formação em Serviço Social; tem atribuição de horas letivas para acompanhamento e apoio teórico, metodológico, técnico e ético ao aluno estagiário; compete-lhe particularmente estabelecer o contato com a instituição no que toca à negociação inicial do estágio a desenvolver e à avaliação do processo. 0 estudante tem também apoio e acompanhamento de um supervisor institucional, com formação preferencialmente em Serviço Social, constitui a instância de relação entre o estagiário e a instituição da qual recebe delegação para fazer o acompanhamento teórico, técnico e ético do aluno durante o processo (Regulamento de Estágio, 2016).

O estudante é o protagonista da experiência realizada no âmbito do contexto de estágio, mas é essencial e importante que este se sinta implicado no seu percurso e aqui a relação entre os supervisores é premente. A relação pedagógica estabelecida e construída no percurso e no processo de aprendizagem é essencial para o desenvolvimento pessoal, académico e profissional do aluno e para a aquisição de competências que the permita uma maior adaptação aos contextos reais. Tanto o supervisor tutorial como o supervisor institucional são um modelo para os estudantes, na medida em que estes têm um papel influenciador no que respeita às práticas, atitudes, relação e transmissão de conhecimentos. Segundo Espinar (2004, p. 59), o supervisor tutorial (diria também o supervisor institucional), é o profissional que demonstra interesse pelo desenvolvimento do aluno como pessoa, como estudante e como futuro profissional. E para isso são também necessárias competências e saberes específicos que os definem enquanto supervisores e, uma das dimensões a não descurar é a relação.

Segundo Postic (2008, p. 13) "a relação pedagógica torna-se educativa quando, em vez de se limitar à mera transmissão do saber, consegue comprometer os seres num encontro onde cada um descobre o outro e ao mesmo tempo se vê a si próprio, a partir daqui começa uma aventura humana (...)". E esta aventura pressupõe presença, diálogo, interação, cumplicidade, empatia e uma enorme vontade de investimento mútuo.

A interação professor-aluno, saudável, complementar, dialógica, só é possível se o professor investe na aprendizagem significativa do estudante, se busca todos os meios de conquistar o estudante para o desafiante processo de se abrir para o novo, de reorientar as marcas da omissão, da passividade e da memorização, de construir conhecimentos e atitudes de forma ativa e autónoma (Santos e Soares, 2011, p. 360). 
O diálogo é fundamental no encontro e no contato a estabelecer entre professoraluno.

Quanto mais o professor compreender a dimensão do diálogo como postura necessária em suas aulas, maior avanço estará conquistando em relação aos alunos, pois desse modo, sentir-se-ão mais curiosos e mobilizados para transformarem a realidade. Quando o professor atua nessa perspectiva, ele não é visto como um mero transmissor de conhecimentos, mas como um mediador, alguém capaz de articular as experiências dos alunos com o mundo (...)" (Santos e Soares, 2011).

Na perspetiva de Alarcão \& Tavares (2003, p. 35), o papel dos supervisores é fundamental para ajudar os estagiários a compreenderem as situações, a saberem agir em situação e a sistematizarem o conhecimento que brota da interação entre a ação e o pensamento". E sublinham que para que este processo se desenrole nas melhores condições, é necessário criar um clima favorável, uma atmosfera afetiva-relacional e cultural positiva, de entreajuda, recíproca, aberta, espontânea, empática (...) (p. 61).

\section{Método}

Para este estudo, optamos por uma metodologia qualitativa. Procuramos conhecer as conceções dos estudantes finalistas da licenciatura em Serviço Social de uma Universidade privada, no concelho de Lisboa. Estes estudantes foram sujeitos a um guião de entrevista sobre supervisão pedagógica, importância do estágio no processo de formação, principais competências do supervisor tutorial e institucional e o papel do supervisor pedagógico numa pedagogia para a autonomia. 0 universo do estudo recaiu sobre 16 estudantes que constituíram uma das turmas do referido curso.

A técnica utilizada para a obtenção de dados junto dos participantes neste estudo exploratório, foi a entrevista semiestruturada. Esta caracterizada "pelo emprego de uma lista de perguntas ordenadas e redigidas por igual para todos os entrevistados, mas de resposta livre ou aberta" (Moreira 2007, p. 206).

Os dados recolhidos foram analisados através da análise de conteúdo que segundo Guerra (1996, p. 62), "tem uma dimensão descritiva que visa dar conta do que 
nos foi narrado e uma dimensão interpretativa que decorre das interrogações do analista face ao objeto de estudo".

\section{Análise e Discussão dos dados}

Procedeu-se à leitura e análise das entrevistas semiestruturadas e procuramos identificar as principais categorias para proceder à interpretação das mesmas. Para a referida análise, procurámos dar voz aos entrevistados, dando sentido aos discursos recolhidos.

\subsection{Noção de supervisão pedagógica}

A noção de supervisão pedagógica tem vários sentidos e significados, para os entrevistados.

Para os estudantes, a supervisão pedagógica tem como objetivo promover o bem-estar do aluno e acima de tudo tem como missão, acompanhar e orientar a vertente prática, metodológica e teórica em contexto de estágio. A supervisão aparece aqui como sendo o acompanhamento, que o aluno tem por parte do professor, tendo presente uma relação de proximidade, para se conseguir um melhor trabalho e consequentemente formar um melhor profissional.

A supervisão pedagógica tem como objetivo principal tentar garantir o bem-estar do aluno e tentar que consiga atingir os seus objetivos, tendo em conta o esforço do mesmo. E2

É o acompanhamento do professor na vertente prática do aluno. E1 A supervisão pedagógica é um acompanhamento metodológico, teórico e prático cujo objetivo é a formação de um melhor profissional. E5 Acompanhamento do aluno quando este se encontra em contexto de estágio. E8

A supervisão pedagógica é ser acompanhado pelo professor em contexto de estágio, mantendo uma relação de proximidade com ele. É importante haver alguma intimidade na supervisão pedagógica porque assim, tanto o professor como o aluno, conseguem fazer um melhor trabalho. E9 A supervisão pedagógica relaciona-se com um acompanhamento tanto ao nível teórico, isto é, de ajuda na construção do relatório, como apoio emocional sobre dúvidas e receios que o estudante sente no estágio. E14 
A supervisão pedagógica implica um bom acompanhamento ao aluno sempre que necessário. E15

A supervisão pedagógica consiste num acompanhamento próximo, junto do trabalho realizado, tendo presente por parte do supervisor: a sinceridade e a valorização necessária.

A supervisão pedagógica consiste num acompanhamento de perto junto do trabalho realizado, disponibilidade por parte do supervisor, sinceridade e valorização quando necessária. E4

Supervisionamento do professor relativamente ao nosso percurso de trabalho. O professor orienta os alunos nas dificuldades. E16

Na perspetiva destes estudantes, a avaliação está presente no processo de formação. E esta também é, uma das dimensões da supervisão pedagógica.

A supervisão pedagógica é ser acompanhado por alguém, a nível dos trabalhos, ser ajudado nas várias fases do mesmo. E ser avaliado ao longo do processo. E3

Consiste em avaliar ao mesmo tempo que são corrigidos os erros cometidos por quem é supervisionado. E13

\subsection{A importância do estágio no processo de formação}

Quando falamos da componente prática da formação, estamos a falar inevitavelmente do estágio e da sua importância no processo ensino aprendizagem do estudante. Para a maioria dos entrevistados, o estágio é a ligação da teoria com a prática e o estágio permite compreender a parte teórica e como esta se insere no contexto prático.

\footnotetext{
É a ligação da teoria com a prática. E13

O estágio é uma forma de compreender a parte teórica e como se insere na prática. E14
}

Os estudantes são unânimes quando referem que o estágio permite ao aluno uma aproximação a diversas realidades, a diversos contextos e a problemáticas diversificadas. 0 estágio surge como uma componente fundamental no processo 
académico do aluno, pois permite o confronto com a realidade e simultaneamente a possibilidade de aplicar técnicas, métodos e ações que ajudam no processo de formação. Um dos estudantes refere que o estágio é uma boa ferramenta para o desenvolvimento pessoal do próprio.

O estágio permite ao aluno uma aproximação a diversas realidades. Permite também o conhecimento e "os fazeres" da parte prática. E1

0 estágio é bastante importante pois é com ele que vemos realmente a realidade e aprendemos a utilizar tudo o que aprendemos. E2

0 estágio tem uma componente fundamental no processo académico do aluno, pois transmite-nos a noção de realidade a que seremos confrontados e a partir daí um conjunto de técnicas, ações, métodos que nos ajudam no presente e futuro. E5

No estágio é-nos permitido vivenciar aquilo que aprendemos ou ouvimos falar durante as aulas. 0 estágio é uma boa ferramenta para o desenvolvimento do estudante. E8

Como mencionado, o estágio possibilita conhecer aprofundadamente a realidade no contexto de trabalho e permite ao aluno um contato privilegiado com a prática profissional. Os estudantes dão extrema relevância à aquisição de competências teórico-operativas. 0 estágio permite adquirir competências, tais como: independência, responsabilidade, maturidade, disponibilidade e também apreender as metodologias da profissão, presentes, no contexto profissional.

0 estágio permite ao aluno conhecer de certo modo a realidade no contexto de trabalho. 0 estágio permite um contato privilegiado com a prática profissional, possibilitando aos alunos construir e adquirir competências técnico-operativas. E16

O estágio é importante no processo de formação e permite competências, tais como, a independência, responsabilidade, maturidade, apreender as metodologias do serviço social, saber como se processa a prática do assistente social para além da teoria. E3

O estágio é um processo bastante vantajoso, não só porque nos dá uma imagem mais alargada da área em que estamos a estudar e futuramente trabalhar, faz com que ganhemos muitas competências como responsabilidade e disponibilidade. E4 
Os estudantes referem que o estágio é fundamental, enquanto exercício prático para a formação profissional e, enquanto espaço de aprendizagem de aquisição de competências e sensibilidade, na forma de agir com os utentes e com os profissionais. Possibilita, ainda, perceber as funções do assistente social, no âmbito da sua prática e permite adquirir uma maior relação de proximidade com o mundo.

É muito importante, o estágio, pois permite ao aluno adquirir competências para a sua formação profissional e adquirir também maior relação de proximidade com o mundo. E7

O estágio é fundamental enquanto exercício prático porque cria desde cedo, competências e sensibilidade na nossa forma de agir enquanto futuros profissionais. Essas competências passam por questões de valores e princípios a ter com o utente. E9

Em contexto de estágio adquire-se competências importantes como, a forma de nos relacionarmos com os utentes, o estágio é um processo de formação importante pois só assim se consegue perceber quais as funções do assistente social. E10

O estágio permite ao aluno ter uma perceção real da sua futura profissão e pôr em prática os conteúdos teóricos, mas também adquirir capacidades e competências que só no âmbito da prática as poderia adquirir. E12

\subsection{Competências do supervisor tutorial}

As competências do supervisor tutorial passam por apoiar, orientar, ouvir, respeitar, avaliar, ajudar o estudante na resolução de dificuldade, ser exigente e apoiar o aluno para este não desmotivar.

Apoiar, orientar, ouvir, respeitar. Espero que me ajude sempre que necessite e, juntamente com o aluno resolver as dificuldades. E2

Ajudar o aluno quando necessita, dar apoio para o aluno não desmotivar, ser exigente com o aluno. Espero que o orientador possa orientar quando o aluno se sente desorientado e ajuda nas coisas que são propostas para serem feitas da melhor forma possíveis. E3 Avaliar, acompanhar e orientar o aluno. E16 
Os estudantes esperam do supervisor pedagógico um docente competente que saiba orientar, que tenha clareza e respeito e leve o aluno a um bom caminho.

Espero do supervisor que seja competente em orientar, que tenha clareza e respeito. E7

Saber acompanhar o aluno, elevá-lo a um bom caminho. E12

O supervisor pedagógico deve estar atento ao trabalho desenvolvido pelo aluno, deve aconselhar, ouvir, escutar, orientar, ser sincero e sensível e ajudar na mudança de atitudes. Os estudantes esperam cooperação, compreensão, amabilidade e um profissional que saiba ser e fazer.

O supervisor tutorial deve estar atento ao trabalho do discente, assim como perceber se está tudo bem com o mesmo. Deve ser disponível e sincero. E4

(...) deve demostrar interesse em tudo o que o aluno faz para poder aconselhar, ajudar a mudar atitudes menos corretas, dar força ao aluno para continuar empenhado. Deve estar disposto a ouvir e a responder a dúvidas do aluno. E8

Acima de tudo deve ser sensível aos alunos. Deve saber orientar, escutar, ensinar, ser bom conselheiro. Apesar de todo o respeito implícito na relação professor aluno deve haver uma relação solidificada. E9

Do supervisor tutorial espera-se cooperação, compreensão, amabilidade, saber ser e fazer. E11

Espera-se que o supervisor pedagógico dê autonomia, crie relação que permita ao aluno expor sentimentos e receios e apoiar a nível teórico.

Do supervisor tutorial espera-se que nos dê autonomia, apoio, conselhos para que tudo corra bem. E10

Dar autonomia ao aluno, criar uma relação que permita ao aluno expor todos os sentimentos e receios e apoiar ao nível teórico. E14 


\title{
3.4 Competências do supervisor institucional
}

Todos os estudantes são unânimes quanto às competências do supervisor institucional, referindo que este deve apoiar, orientar, ouvir, acompanhar, dar autonomia e supervisionar todo o trabalho e percurso do aluno, em contexto real.

\begin{abstract}
Apoiar, orientar, ouvir, respeitar. Espero que me ajude sempre que necessite e, juntamente com o aluno resolver as dificuldades. E2

Deve acompanhar todo o trabalho do aluno no âmbito do estágio, integrá-lo e orientá-lo nas tarefas de assistente social e partilhar a sua experiência. E12

Acompanhar durante todo o percurso, estando presente e transmitindo ensinamentos. Dar autonomia, mas expor quais as funções e desafios ao serviço social na instituição. E14
\end{abstract}

Apoiar, acompanhar e supervisionar. E16

Estes estudantes esperam do supervisor institucional, ensinamentos sobre técnicas, formas, metodologias para se tornarem melhores profissionais; que transmitam conhecimentos teóricos sobre a área onde estão inseridos e lhes apresentem a melhor maneira de trabalhar enquanto assistentes sociais.

De um supervisor institucional espero ensinamentos na área onde estou inserida, acompanhamento e ajuda durante todo o processo de estágio, ensinamento de técnicas, formas e metodologias para me tornar uma melhor profissional e mais competente e transmissão de conhecimentos teóricos sobre a área onde estou inserida. E5

De um supervisor institucional espera-se que ensine e mostre a melhor maneira de trabalhar enquanto assistente social. E10

O supervisor institucional deve (...) proporcionar ao aluno, o mais possível, a realidade profissional. E13

Procuram no supervisor institucional, um profissional competente e exemplar e que corrija o aluno no momento para que, este se torne num melhor profissional.

O supervisor institucional tem a oportunidade de corrigir o aluno no momento em que este erra ou age de uma forma menos própria. E8 
Acima de tudo deve ser exemplar enquanto profissional. Procura-se uma relação profissional e formal onde sejamos indicados do caminho a seguir no estágio e disciplinados, para sermos melhores profissionais. E9

O supervisor institucional é uma pessoa muito importante no processo de aprendizagem do estudante, pois constitui a instância de relação entre o estudante/ estagiário e a instituição onde efetua a sua prática.

\subsection{Relação pedagógica (professor/aluno) no processo de formação}

Os estudantes são os protagonistas da experiência realizada no âmbito do contexto de estágio e esperam da relação professor/aluno uma relação de abertura, diálogo, flexibilidade, sinceridade e de compreensão.

Abertura, flexibilidade, sinceridade e compreensão. E1

Tem que existir uma relação entre o professor e o aluno para poder perceber os problemas que existem. Tem que haver mais abertura e diálogo de ambas as partes. E7

As dimensões fundamentais, apontadas pelos estudantes, para o estabelecimento de uma boa relação pedagógica é a confiança mútua, a entre ajuda, o respeito e o incentivo ao aluno fazendo valer as capacidades e competências do mesmo.

De confiança mútua e respeito e ajuda de modo a ultrapassar as dificuldades. E2

Respeito, confiança e entre ajuda. E3

Uma relação de confiança e de respeito. Considero importante também a exigência, mas apoio em todas as dificuldades. E14

Deverá haver uma relação de confiança e incentivo ao aluno para fazer valer das suas capacidades e competências. E15

É importante que na relação professor / aluno haja essencialmente respeito, troca de ideias e sinceridade. E4

Deve estar presente o respeito, o cuidado, a igualdade de direitos e deveres, a transmissão de conselhos nas dificuldades sentidas no processo de formação académica. E5 
Uma relação de proximidade e uma relação de ajuda carregada de respeito são fundamentais para o sucesso do estudante.

Uma relação de intimidade quase como um elo familiar, mas carregado de respeito. E9

Deve ser uma relação de ajuda, ou seja, quando necessário, o professor estar presente e que nos ajude da melhor maneira. E10

Uma relação de proximidade ótima onde ambos conheçam os seus papeis e que trabalhem em prol do sucesso, o aluno deve comprometer-se nas suas tarefas e o professor exigir. E12

Na perspetiva dos estudantes, a relação de proximidade entre professor/aluno é essencial, simultaneamente com o distanciamento necessário.

Uma relação de proximidade e simultaneamente de distanciamento. E11 Uma relação de empatia, proximidade, mas com o distanciamento necessário. E16

\subsection{Papel do supervisor pedagógico numa pedagogia para a autonomia}

Os estudantes são unânimes quanto ao papel do supervisor pedagógico numa pedagogia para a autonomia, referindo que este papel passa essencialmente pelas seguintes dimensões: ajudar o aluno a ganhar ferramentas para se lançar no mercado de trabalho; dar liberdade para o aluno errar; dar espaço para o aluno sentir dúvidas e se sentir autónomo; criar espaços para esclarecimento de dúvidas; orientar o aluno na escolha do melhor caminho; existir um acompanhamento semanal ou quinzenal; estar disponível e presente; ser exigente e, ter um papel motivador e de esperança para o desenvolvimento do estudante.

Ajudar o aluno a ganhar ferramentas e competências para se lançar no mercado de trabalho dentro da área de formação. E1

Dar liberdade para o aluno errar, pois a errar é que se aprende. E2 O papel do supervisor pedagógico numa pedagogia para a autonomia dos alunos é falar bem acerca das coisas que têm que ser feitas, sem dar ajuda de imediato ao aluno, mas sempre dando uma pequena ajuda. E3 
Para o aluno se sentir autónomo é necessário que o supervisor dê algum espaço para que o mesmo tenha dúvidas. E4

É importante o espaço que o supervisor dá ao aluno para a sua própria aquisição de conhecimentos, dificuldades para uma autonomia do aluno, sendo que o acompanhamento semanal ou quinzenal é essencial. E5

Penso que um espaço para esclarecimento de dúvidas seria bom para uma maior autonomia dos alunos. E8

O supervisor pedagógico deve apoiar, mas dando a autonomia necessária e a liberdade para que este consiga fazer o seu caminho. E10

Para que os alunos sejam autónomos o supervisor deve referir o que tem que ser feito e quando, esclarecer as dúvidas, mas dar espaço ao aluno de fazer o trabalho ao seu ritmo até porque o aluno se testa a si próprio. E13 A autonomia é importante durante o estágio. Devendo dar autonomia, mas apoiar em todas as questões. 0 mais importante é a relação de confiança. E14

O supervisor deve orientar, ajudar o aluno a escolher o melhor caminho, deve estar presente e disponível, mas claro que a exigência da sua disponibilidade por parte do aluno deve ser contida, para que este mantenha a sua autonomia relativamente ao seu trabalho. E12

Deverá estar sempre presente, mas deve dar espaço necessário aos alunos e deve incentivá-los a construir e a percorrer o seu próprio caminho. E16 O supervisor pedagógico detém um papel importante para a autonomia do aluno e sucesso académico. Tem um papel de ser motivador e de esperança para o desenvolvimento do aluno. E15

\section{Resultados preliminares}

O presente estudo permite avançar com a ideia de que a supervisão pedagógica adquire um papel ativo de interação, partilha e mediação entre o professor e o aluno e a relação e interação partilhada com o supervisor institucional é a via privilegiada de conhecimento e de aperfeiçoamento na formação em Serviço Social.

Os dados possibilitam assegurar que os estudantes entrevistados têm presente o que consiste a supervisão pedagógica no processo de formação; que competências têm o supervisor tutorial e o supervisor institucional, referindo que ambos contribuem para o desenvolvimento das capacidades e competências do estudante, 
necessárias para o exercício da profissão; a relação de proximidade, de ajuda e de apoio são essenciais no processo de aprendizagem e, o papel de um supervisor pedagógico tem como missão, orientar o estudante numa via de autonomização.

A supervisão pedagógica assume, assim, um papel transformador nos estudantes e nas suas práticas. A participação ativa dos alunos no seu processo de desenvolvimento académico e pessoal, cria um sentimento de pertença, responsabilidade e de identidade.

Desejamos que o presente estudo contribua para aperfeiçoar o conhecimento sobre a supervisão pedagógica em contexto de formação académica; permita conscientizar para a importância do estágio, enquanto espaço de aprendizagem em contexto real e, permita refletir para a necessária e importante relação a construir entre professor/estudante. Uma relação de proximidade e de ajuda e, simultaneamente, uma relação que possibilite a distância necessária para que o aluno trace o seu caminho com autonomia e confiança.

\section{Bibliografia}

Alarcão, I. \& Soares, J. (2003). Supervisão da prática pedagógica. Uma perspectiva de desenvolvimento e aprendizagem. Coimbra: Edições Almedina ( $2^{\mathrm{a} e d i c ̧ a ̃ o) . ~}$

Alarcão, I. (1996). Formação reflexiva de professores: estratégias de supervisão. Porto: Porto Editores.

Almeida, S. (s/d). A importância do estágio supervisionado na formação profissional do assistente social. Acedido a 29 de janeiro de 2017, em http://www.cress-mg.org.br/ arquivos/simposio/A\%20IMPORT\%C3\%82NCIA\%20DO\%20EST\%C3\%81GIO\%20SUPERVISIONADO\%20NA\%20FORMA\%C3\%87\%C3\%830\%20PROFISSIONAL\%20DO\%20ASSISTENTE\%20SOCIAL. pdf

Espinar, S. et al. (2004). Manual de tutoría universitária. Recursos para la accion. Barcelona: Educación Universitaria.

Freitas, M. D. (2013). Supervisão na formação em Serviço Social. Tese de Doutoramento policopiado. Lisboa: UCP.

Guerra, I. (2006). Pesquisa Qualitativa e Análise de Conteúdo - Sentidos e formas de uso. Estoril: Principia.

Moreira, C. D. (2007). Teorias e práticas de investigação. Lisboa: Universidade Técnica de Lisboa. ISCSP. 
Moreira, M. A. (2004). O papel da supervisão numa pedagogia para a autonomia. In Pedagogia para a Autonomia: reflectir e agir estrategicamente. Actas do $2^{\circ}$ Encontro do Grupo de Trabalho - Pedagogia para a Autonomia (GT-PA), Braga

Prates, M. L.et al. (2010). Liderança: supervisão e aprendizagem partilhada na escola atual. Acedido a 29 de janeiro de 2017, em https://bibliotecadigital.ipb.pt/bitstream/10198/3446/1/41-134-1-PB.pdf

Postic, M. (2008). A Relação pedagógica. Lisboa: Padrões Culturais Editora.

Regulamento de Estágios da Licenciatura em Serviço Social (2016), Lisboa: UHLT.

Santos, C. \& Soares, S. (2011). Aprendizagem e relação professor aluno na universidade: duas faces da mesma moeda. Est. Aval. Educ., São Paulo, v. 22, n. 49, p. 353-370, maio/ ago. Acedido a 29 de janeiro de 2017, em http://www.fcc.org.br/pesquisa/publicacoes/eae/arquivos/1641/1641.pdf

Soares, M. (s/d). A supervisão pedagógica: uma leitura dos tempos. Acedido a 29 de janeiro de 2017, em http://www.cfaematosinhos.eu/Supervisao\%20Pedagogica.pdf

Vieira, F. (2009). Para uma visão transformadora da supervisão pedagógica. Acedido a 29 de janeiro de 2017, em http://www.scielo.br/pdf/es/v30n106/v30n106a10.pdf 